\title{
Effects of alkylphenols on the biotransformation of diuron and enzymes involved in the synthesis and clearance of sex steroids in juvenile male tilapia (Oreochromus mossambica)
}

\author{
Andréia A. Felício ${ }^{\mathrm{a}, \mathrm{c}}$, Jordan Crago ${ }^{\mathrm{b}, \mathrm{c}}$, Lindley A. Maryoung ${ }^{\mathrm{b}, \mathrm{c}}$, Eduardo A. Almeida ${ }^{\mathrm{a}, \mathrm{c}, *}$, \\ Daniel Schlenk ${ }^{\mathrm{c}, *}$ \\ a Department of Chemistry and Environmental Sciences, Universidade Estadual Paulista (IBILCE/UNESP), Rua Cristóvão Colombo, 2265, CEP - 15054-000, \\ São José do Rio Preto, SP, Brazil \\ ${ }^{\mathrm{b}}$ Department of Natural Sciences, Fundação Universidade Regional de Blumenau, Av. Antonio da Veiga 140, Itoupava Seca, 89030-903, Blumenau, SC, Brazil \\ c Department of Environmental Sciences, University of California, Riverside, Riverside, CA 92521, USA
}

\section{A R T I C L E I N F O}

\section{Article history:}

Received 1 June 2016

Received in revised form 18 October 2016

Accepted 19 October 2016

Available online 22 October 2016

\section{Keywords:}

Diuron

Alkylphenols

Anti-androgen

Vitellogenin

Biotransformation

Cytochrome P450

\begin{abstract}
A B S T R A C T
Previous studies using in vivo bioassay guided fractionation indicated that the herbicide diuron (3(3,4-dichlorophenyl)-1,1-dimethylurea) and alkylphenol (AP)-containing surfactants were detected in fractions of extracts that induced the estrogenic biomarker, vitellogenin in fish exposed to surface water extracts from the United States. However, when the compounds were evaluated individually using in vivo estrogenic assays or in vitro estrogen receptor assays, estrogenic activity was not observed. Since APs have been shown to alter activity and content of cytochrome P450s (CYP) which convert diuron to potential estrogenic metabolites, the hepatic biotransformation of diuron was measured with and without a 7 day pretreatment of $p$-Octylphenol (OP) and p-Nonylphenol (NP) at low (OP $13 \mathrm{ng} / \mathrm{L}+\mathrm{NP} 91 \mathrm{ng} / \mathrm{L}$ ), and high concentrations (OP $65 \mathrm{ng} / \mathrm{L}+\mathrm{NP} 455 \mathrm{ng} / \mathrm{L}$ ) in juvenile male Nile tilapia (Oreochromus niloticus). Pre-treatment with the OP/NP (AP) mixture caused elevated levels of NADPH-catalyzed formation of 3,4dichlorophenyl- $N$-methylurea (DCPMU) but not 3,4-dichlorophenylurea (DCPU). Fish were also treated with nominal concentrations of low $(40 \mathrm{ng} / \mathrm{L})$ and high $(200 \mathrm{ng} / \mathrm{L})$ diuron and each of its three degradates/metabolites: DCPMU, DCPU and 3,4-dichloroaniline (DCA). Additional treatments were conducted with APs and Diuron as a mixture at the low concentrations which mimicked concentrations observed in surface waters. Hepatic vitellogenin (Vtg) mRNA was induced by exposure to the high concentrations of Diuron, as well as DCPMU and DCPU in both concentrations. Brain cytochrome P450 aromatase activity was generally diminished by diuron, its metabolites, and the AP/diuron mixtures. $17 \beta$-Hydroxysteroid dehydrogenase (17 $\beta$ HSD) levels were also reduced by DCPMU and DCA in the lower concentrations, but not by higher concentrations. While the AP mixture reduced $17 \beta \mathrm{HSD}$, the AP/diuron mixture induced testosterone $(\mathrm{T})$ biosynthesis at the single concentration tested. Although CYP3A expression was induced by all diuron metabolites, it was unchanged by the AP mixture. These data indicate that mixtures of AP and diuron enhanced the formation of the metabolite (DCPMU) which induced vitellogenin, and reduced $\mathrm{T}$ biosynthetic enzymes (17ßHSD inhibition). Overall, these data showed that APs may have induced the biotransformation of diuron to at least one metabolite, that may disrupt androgen biosynthesis and potentially alter steroid feedback pathways in the central nervous system.
\end{abstract}

(c) 2016 Elsevier B.V. All rights reserved.

\footnotetext{
* Corresponding authors at: Department of Environmental Sciences, University of California, Riverside, Riverside, CA 92521, USA.

E-mail address: daniel.schlenk@ucr.edu (D. Schlenk).
}

\section{Introduction}

Previous studies using in vivo bioassay guided fractionation for estrogenic activity in water extracts from the Central Valley and San Francisco Bay Delta in California (USA) identified Diuron (3-(3,4dichlorophenyl)-1,1-dimethylurea) and alkylphenols in estrogenic fractions of water extracts (Schlenk et al., 2012). Diuron is one of the most widely used herbicides for sugar cane cultivation in 
Brazil (Lourencetti et al., 2008) and a general use herbicide in the United States (Tomlin, 1994). Alkylphenols are derived primarily from akylphenol ethoxylates which are routinuely used as surfactants in a number of applications including pesticide formulations (Xie et al., 2005). When the individual compounds (diuron, octylphenol and $p$-nonylphenol) were administered to primary hepatocytes of rainbow trout (Oncorhynchus mykiss) at ambient concentrations, estrogenic activity (induction of vitellogenin mRNA) was not observed (Schlenk et al., 2012). Similarly, when male Japanese medaka (Oryzias latipes) were exposed to the individual compounds, hepatic vitellogenin protein was not observed. However, when diuron was combined with several alkylphenol ethoxylates and alkylphenols as well as the pyrethroid, bifenthrin, which was also detected in bioactive fractions, estrogenic activity was observed in the in vivo assays, but not the in vitro assays (Schlenk et al., 2012).

Diuron has also been shown to be anti-androgenic in vitro (Orton et al., 2009), in vivo (Pereira et al., 2015) and impair steroidogenesis at relatively high concentrations (15.6-7.3, and $14.5 \mathrm{mg} / \mathrm{L}$, respectively) (Vinggaard et al., 2000). Since responses to the mixtures were only noted in vivo during previous studies, the potential targets for diuron and/or the other compounds observed in estrogenically active water extracts are unclear. One possible mechanism may involve the conversion of diuron to other compounds with endocrine activity leading to feminization. In mammals, diuron undergoes biotransformation to 3,4-dichloroaniline (DCA), 3,4-dichlorophenylurea (DCPU) and 3,4dichlorophenyl- $N$-methylurea (DCPMU) (Tixier et al., 2002; Hodge et al., 1967; Abass et al., 2007). Cytochrome P450 has been shown to be primarily responsible for the demethylation of diuron in mammals to DCPMU and DCPU (Abass et al., 2007), but its role in fish biotransformation is unclear.

Each metabolite/degradate weakly binds to the bovine androgen receptor, with relative binding affinities between 0.002 and $0.01 \%$ of the affinity of dihydrotestosterone (Orton et al., 2009). DCA, DCPU, and DCPMU all reduced plasma testosterone and 11keto-testosterone along with gonadal somatic indices, diameter of seminiferous tubules and mean percentages of germ cells in male tilapia (Pereira et al., 2015). However, the mechanism of the antiandrogenic activity was not evaluated.

While the androgen receptor may be a potential target for diuron and its metabolites, a second target may be the hypothalamic-pituitary-gonadal axis which synthesizes and secretes gonadotropic and gonadal steroid hormones, and reproductive process modulators (Agulleiro et al., 2006). These hormones play a key role in fish gametogenesis (Mylonas et al., 2010). In males, for example, gonadal steroids (11-ketotestosterone and testosterone) mediate spermatogonial proliferation and spermiation (Ohta et al., 2007). Since diuron impaired the biosynthesis of these reproductive hormones in fish (Vinggaard et al., 2000; Pereira et al., 2015), the aim of this study was to evaluate the effects of diuron with and without combination of alkylphenols as well as diuron metabolites on two enzymes that are involved in testosterone biosynthesis and metabolism (17 HHSD and aromatase) as well as xenobiotic biotransformation and steroid clearance (CYP3A) in juvenile male tilapia, Oreochromis mossambicus.

\section{Materials and methods}

\subsection{Chemicals}

All chemicals were 99\% pure based on manufacturers information. Diuron and metabolites were ordered from Sigma-Aldrich Chemical Co (St. Louis, Mo).
Table 1

Treatment groups for diuron, metabolite and akylphenol mixture exposures.

\begin{tabular}{ll}
\hline Group number & Treatment \\
\hline 1 & Control \\
2- diuron low & $40 \mathrm{ng} / \mathrm{L}$ of diuron \\
3- diuron high & $200 \mathrm{ng} / \mathrm{L}$ of diuron \\
4- DCPMU low & $40 \mathrm{ng} / \mathrm{L}$ of DCPMU \\
5- DCPMU high & $200 \mathrm{ng} / \mathrm{L}$ of DCPMU \\
6- DCPU low & $40 \mathrm{ng} / \mathrm{L}$ of DCPU \\
7- DCPU high & $200 \mathrm{ng} / \mathrm{L}$ of DCPU \\
8- DCA low & $40 \mathrm{ng} / \mathrm{L}$ of DCA \\
9- DCA high & $200 \mathrm{ng} / \mathrm{L}$ of DCA \\
10-AP mixture low & $13 \mathrm{ng} / \mathrm{L}$ of OP $+91 \mathrm{ng} / \mathrm{L}$ of NP \\
11-AP mixture high & $65 \mathrm{ng} / \mathrm{L}$ of OP $+455 \mathrm{ng} / \mathrm{L}$ of NP \\
12-AP/Diuron mixture & diuron $40 \mathrm{ng} / \mathrm{L}+13 \mathrm{ng} / \mathrm{L}$ of $\mathrm{OP}+91 \mathrm{ng} / \mathrm{L}$ of NP \\
\hline
\end{tabular}

\subsection{Test organisms}

Juvenile male Oreochromis mossambicus, were selected as model organisms because of their worldwide use as a species for aquaculture in the USA and Brazil. Individuals aged one month weighed $78.23 \mathrm{~g} \pm 3.07 \mathrm{~g}$ and had standard lengths of $15.29 \mathrm{~cm} \pm 0.16 \mathrm{~cm}$. They were obtained from Blue and Beyond Fisheries (Desert Hot Springs, California). Gender was confirmed by microscopic analyses post-mortem. This work was approved by UCR IACUC \# 2010-0004.

\subsection{Exposure experiments}

To a $20 \mathrm{~L}$ aquarium, $18 \mathrm{~L}$ of water and one fish was added prior to the addition of chemicals. There were 12 treatment groups, with five fish per group creating five replicates. The temperature was maintained at $28 \pm 2{ }^{\circ} \mathrm{C}$ and water was constantly aerated. Fish were acclimated for five days in their respective aquarium before exposure. During the exposure period fish were not fed and the water was changed every two days, to maintain toxicant concentrations and control ammonia concentrations, which were determined throughout the experiment.

The groups of the experiment are described in Table 1. Low concentrations used in this experiment were based upon the measurements observed in surface waters of the San Francisco Bay Delta (Schlenk et al., 2012). High concentrations were arbitrary 5 fold increases.

After seven days of exposure all fish were collected, anesthetized, and tissues (brain and liver) were collected and stored in $-80^{\circ} \mathrm{C}$, for analysis.

\subsection{Fish microsome isolations}

Liver and brain were homogenized using the methods of Lavado et al. (2004) with minor modifications. Gonads were not measured because the tissues did not provide enough biomass. Tissues were homogenized (1:5, w/v) in Phosphate Buffer (100 mM, pH 7.4) containing $100 \mathrm{mM}$ of $\mathrm{KCl}$ and $1 \mathrm{mM}$ of EDTA. The homogenized samples were centrifuged at $1500 \times \mathrm{g}$ for $15 \mathrm{~min}$ at $4{ }^{\circ} \mathrm{C}$ and the resulting supernatant centrifuged again at $12,000 \times \mathrm{g}$ for $12 \mathrm{~min}$ at $4{ }^{\circ} \mathrm{C}$. The supernatant from this step was centrifuged again at $100,000 \times g$ for $60 \mathrm{~min}$ to obtain the microsomal fraction as a pellet. The pellet was re-suspended in 1:10 (w/v) in Phosphate Buffer ( $100 \mathrm{mM}, \mathrm{pH} 7.4$ ) containing $100 \mathrm{mM}$ of $\mathrm{KCl}, 1 \mathrm{mM}$ of EDTA and $20 \%$ of Glycerol.

For protein quantification, the Bradford (1976) method was used with bovine serum albumin as standard.

\subsection{Diuron biotransformation}

Liver microsomal fractions of fish from groups 3 (exposed to $200 \mathrm{ng} / \mathrm{L}$ of diuron), 10 (exposed to $13 \mathrm{ng} / \mathrm{L}$ of OP $+91 \mathrm{ng} / \mathrm{L}$ of NP), 
and 11 (exposed to $65 \mathrm{ng} / \mathrm{L}$ of $\mathrm{OP}+455 \mathrm{ng} / \mathrm{L}$ of NP) were incubated for $30 \mathrm{~min}$ at $30^{\circ} \mathrm{C}$ in $100 \mathrm{mM}$ Tris- $\mathrm{HCl}$ buffer ( $\mathrm{pH}$ 7.4) with $100 \mu \mathrm{M}$ of diuron and $7.5 \mathrm{mM}$ of NADPH. An additional $7.5 \mathrm{mM}$ of NADPH was again mixed with the incubation for another $30 \mathrm{~min}$. The reaction was stopped with $250 \mu \mathrm{L}$ of ice cold acetonitrile to precipitate proteins and the internal standard $(100 \mu \mathrm{M}$ caffeine) was added. Recovery rates were $60-70 \%$. Sample was centrifuged at $14,000 \times g$ for $10 \mathrm{~min}$ and the supernatant was collected for HPLC analyses of DCPMU, DCPU and DCA.

HPLC analyses were performed on a SCL-10AVP Shimadu HPLC System equipped with a $250 \times 4.6 \mathrm{~mm}$ Hypersil ODS C18 $(5 \mu \mathrm{m})$ reverse-phase column (ThermoFisher Scientific Inc, Waltham, MA) using an absorbance of $250 \mathrm{~nm}$ for quantification. The mobile phase an isocratic $50 \%$ mixture of acetonitrile and water with a $1 \mathrm{~mL} / \mathrm{min}$ flow rate. Absorbance of eluates was measured at $254 \mathrm{~nm}$. Quantification of the metabolites was attained through linear extrapolation from standard curves employing 5 concentrations of each compound.

\subsection{CYP3A immunoblot analysis}

Microsomal CYP3A from liver was determined by Western immunoblot using the method of Lavado et al. (2004) with minor modifications. Microsomes were boiled at $95^{\circ} \mathrm{C}$ for $5 \mathrm{~min}$ in SDSPAGE buffer and $10 \mu \mathrm{g}$ of protein was separated by electrophoresis using $10 \%$ SDS-polyacrylamide gels, first for $30 \mathrm{~min}$ in $60 \mathrm{~V}$ and after for $80 \mathrm{~min}$ in $150 \mathrm{~V}$, and transferred to Nitrocellulose Membranes using a Trans-Blot ${ }^{\circledR}$ Semi-Dry Transfer Gel (Bio-Rad Laboratories, Hercules, CA, USA) for $30 \mathrm{~min}$ in $15 \mathrm{~V}$. They were probed using a $1: 2000$ dilution $(\mathrm{v} / \mathrm{v})$ of primary rabbit anti-human CYP3A4, incubating overnight at $25^{\circ} \mathrm{C}$. The membrane was rinsed three times with Tris-buffered saline containing $0.2 \%$ Tween $20(\mathrm{v} / \mathrm{v})$ and $0.5 \%$ gelatin $(\mathrm{w} / \mathrm{v})$. The membranes were incubated for $1 \mathrm{~h}$ with Goat Anti-Rabbit IgG (H+L)-AP Conjugate (Bio-Rad, Hercules, CA, USA) and using the Alkaline Phosphatase Conjugate Substrate Kit (BioRad Laboratories) developed. Quantification was carried out with a ChemiDoc ${ }^{\text {TM }}$ XRS+ System (Bio-Rad) using Image Lab Software (Bio-Rad) to measure optical density units/mg protein. Loading was normalized by total protein measurements.

\subsection{Vitellogenin analysis}

Vitellogenin messenger RNA was measured using the method of Lavado et al. (2013). Total RNA from the liver was extracted using RNeasy ${ }^{\circledR}$ Lipid Tissue MiniKit (QIAGEN; Valencia, CA, USA). For cDNA preparation High Capacity cDNA Reverse Transcription Kit (Applied Biosystems ${ }^{\mathrm{TM}}$; Foster City, CA, USA) was used, and the quality of the extracted RNA was evaluated by spectrophotometry (Nanodrop). Real time quantitative PCR was performed using “iScript ${ }^{\mathrm{TM}}$ One Step" RT-PCR kits with SYBR ${ }^{\circledR}$ Green (BioRad; Hercules, CA, USA). Vitellogenin primers ( $\mathrm{R}$ - 5'GTC CTC CCT GAT CAC ATTA GTT G $3^{\prime}$ and $\mathrm{F}-5^{\prime}$ CTC AGT TGC TGG AGT ACA GTG $3^{\prime}$ ) and EF1-alpha primers ( $\mathrm{R}-5^{\prime} \mathrm{GCA}$ TAA GCC ATG CCT TGA GTA TAG 3' and $\mathrm{F}-5^{\prime} \mathrm{CGG}$ TGT CAT CAA GTC CGT TAT C $3^{\prime}$ ) for housekeeping were used. Analyses were conducted using an iCycler-MyIQ Single Color Real-Time PCR Detection System (Bio-Rad; Hercules, CA. USA) and data analyzed with IQ5 (Bio-Rad; Hercules, CA, USA). Primers were optimized based on annealing temperature, template concentration, and primer concentration. $250 \mathrm{nM}$ of each primer was added to $25 \mu \mathrm{L}$ PCR reactions containing SYBR Green RT-PCR Reaction Mix, and $100 \mathrm{ng}$ of cDNA sample. Thermocycling parameters were as follows: 5 mins at $95^{\circ} \mathrm{C}$; 40 cycles of $10 \mathrm{~s}$ at $95^{\circ} \mathrm{C}$ and $30 \mathrm{~s}$ at $57^{\circ} \mathrm{C}$. At the end of each cycle fluorescence data was collected. A melting curve analysis was run between $60^{\circ} \mathrm{C}$ and $95^{\circ} \mathrm{C}$ following the amplification reaction. The $\mathrm{C}(\mathrm{t})$ was selected to be in the linear phase of amplification.

\subsection{Liver $17 \beta$-Hydroxysteroid dehydrogenase enzyme activity}

Liver microsomal fractions were incubated in $50 \mathrm{mM}$ of Tris- $\mathrm{HCl}$ Buffer (pH 7.4) with $0.2 \mu \mathrm{M}\left[{ }^{3} \mathrm{H}\right]$ androstenedione $(150,000 \mathrm{dpm})$, $10 \mathrm{mM} \mathrm{MgCl} 2$ and $300 \mu \mathrm{M}$ NADPH in a total volume of $250 \mu \mathrm{L}$, as described in Thibaut and Porte (2004). Samples were incubated for $15 \mathrm{~min}$ in $30^{\circ} \mathrm{C}$. To stop reaction $250 \mu \mathrm{L}$ of acetonitrile was added and the solution was centrifuged $1500 \mathrm{~g}$ for $10 \mathrm{~min}$. The supernatant was collected and analyzed in HPLC. HPLC analyzes was performed on a SCL-10AVP ShimaduHPLC System equipped with a $250 \times 4.6 \mathrm{~mm}$ Hypersil ODS C18 $(5 \mu \mathrm{m})$ reverse-phase columm (ThermoFisher Scientific Inc, Waltham, MA), in a $254 \mathrm{~nm}$ of wave-length. Separation of androstenedione and metabolites was performed at $1 \mathrm{~mL} / \mathrm{min}$ with a mobile phase composed of (A) 75\% of water and $25 \%$ of acetonitrile, and (B) $25 \%$ of water and $75 \%$ of acetonitrile. Chromatographic peaks was monitored by on-line radioactivity detection with Radioflow detector LB 509 (Berthold Technologies, BadWildbad, Germany) using Flo-Scint 3 (Packard BioScience, Groningen, The Netherlands) as scintillation cocktail.

\subsection{Brain aromatase enzyme activity}

Since animals did not have adequate gonadal tissue for aromatase analyses, the brain microsomal fraction was used to measure aromatase activity, using the tritiated-water method as described in Morcillo et al. (1999), with some changes. Each sample was adjusted to $2 \mathrm{mg} / \mathrm{ml}$ of protein and was incubated at $25^{\circ} \mathrm{C}$ for $30 \mathrm{~min}$ with $100 \mathrm{mM}$ Tris- $\mathrm{HCl}(\mathrm{pH} 7.6), 10 \mu \mathrm{M}$ unlabeled androstenedione, $4.35 \mathrm{mM}$ NADPH and $0.1 \mathrm{Ci} / \mu \mathrm{L}[1 \beta-$ ${ }^{3} \mathrm{H}$ ]-androstenedione. Assay blanks containing $100 \mu \mathrm{L}$ of buffer instead of microsomes were used for every run. The reaction was stopped by placing the tube on ice; organic metabolites and the excess of substrate were immediately eliminated from the aqueous phase by extraction with methylene chloride. Following this, a suspension containing $2.5 \%(\mathrm{w} / \mathrm{v})$ activated charcoal and $0.25 \%$ dextran in Milli-Q water was added. The mixture was centrifuged and the supernatant counted for ${ }^{3} \mathrm{H}$ radioactivity.

\subsection{Statistical analyses}

Statistical analyses were conducted using Prism5 v5.0a software. Prior to statistical analysis, all data were analyzed to meet the normality and variance assumptions for parametric tests. For normally distributed data, an initial one-way ANOVA was performed to evaluate the differences between treatments. If a P-value less that 0.05 was observed, it was considered statistically significant, and if there was significance, the Tukey's multiple range test was preformed to determine differences between groups. If data did not meet assumptions of the parametric test, a Kruskal-Wallis test and two-tailed multiple comparisons Dunn's test was used.

\section{Results}

\subsection{Biotransformation}

In vitro incubations of diuron with liver microsomes from untreated tilapia catalyzed the NADPH-dependent formation of DCPU, and DCPMU from diuron (Table 1). Fish pretreated with AP significantly increased the rates of DCPMU formation 3-fold after treatment (Table 2).

To evaluate the potential role of CYP3A in the biotransformation of diuron, expression of hepatic CYP3A was measured after treatment with Diuron, its metabolites and the AP mixture. CYP3A was 
Table 2

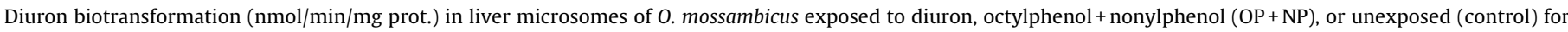
7 days. Each value represents the mean value of 5 replicates $\pm S D$.

\begin{tabular}{|c|c|c|c|c|}
\hline & Control & Diuron (200 ng/L) & $\mathrm{OP}+\mathrm{NP}(13+91 \mathrm{ng} / \mathrm{L})$ & $\mathrm{OP}+\mathrm{NP}(65+455 \mathrm{ng} / \mathrm{L})$ \\
\hline DCPMU & $0.18 \pm 0.05$ & $0.40 \pm 0.28$ & $0.58 \pm 0.36^{*}$ & $0.31 \pm 0.09$ \\
\hline DCPU & $0.08 \pm 0.05$ & $0.16 \pm 0.14$ & $0.21 \pm 0.19$ & $0.07 \pm 0.03$ \\
\hline DCA & ND & ND & ND & ND \\
\hline
\end{tabular}

$\mathrm{ND}=$ Not detected

${ }^{*}(\mathrm{p}<0.05)$ compared to the control group.

Table 3

Effects of Diuron, its metabolites/degradates and APs alone and in mixtures on hepatic CYP3A-like expression in 0 . mossambicus after 7 days of exposure. Each value represents the mean \pm SD of 5 replicates.

\begin{tabular}{lll}
\hline Compound & Concentration $(\mathrm{ng} / \mathrm{L})$ & CYP3A expression \\
\hline Control & - & $1.07 \pm 0.11$ \\
Diuron & 40 & $0.65 \pm 0.20$ \\
& 200 & $1.60 \pm 0.24$ \\
DCPMU & 40 & $0.96 \pm 0.16$ \\
& 200 & $4.26 \pm 0.62^{*}$ \\
DCPU & 40 & $1.49 \pm 0.22$ \\
& 200 & $4.38 \pm 1.08^{*}$ \\
DCA & 40 & $1.45 \pm 0.30$ \\
& 200 & $2.04 \pm 0.52^{*}$ \\
OP + NP & $13+91$ & $0.40 \pm 0.09^{*}$ \\
& $65+455$ & $0.52 \pm 0.15$ \\
OP + NP+ Diuron & $13+91+40$ & $0.86 \pm 0.48$
\end{tabular}

${ }^{*} \mathrm{p} \leq 0.05$.

significantly induced in livers of tilapia following treatment with the diuron metabolites, reduced by AP, and unchanged following pretreatment with AP/diuron (Table 3).

\subsection{Estrogenic activity}

Vitellogenin expression was statistically higher after seven days of exposure to the high concentrations of Diuron (high concentration), as well as DCPMU and DCPU in both concentrations. Induction was also observed in animals treated with the low concentration of DCA (Fig. 1A). Although trends toward an increase in Vtg were observed with the AP mixture, the only significant difference was observed between diuron treatments and the $\mathrm{AP} /$ diuron treatment $($ ANOVA $\mathrm{p}=0.05)$ (Fig. 1B).

\subsection{Steroid biosynthetic enzymes}

Aromatase activity in the brain was statistically lower after exposure to the high Diuron treatment. DCPMU in both concentrations, and the low concentration of DCPU also diminished activity (Fig. 2A). Treatment with DCA failed to alter activities. AP treatment with and without the low Diuron concentration also caused significant reductions in aromatase activities (Fig. 2B).

$17 \beta$ HSD activity was significantly reduced by treatment of fish with the low concentration of DCPMU and DCA (Fig. 3A). Pretreatment with AP also reduced 17ßHSD. However, combinations of diuron with AP led to a non-significant increase in activity (Fig. 3B).

\section{Discussion}

Previous studies indicated that APs and Diuron were observed in estrogenic fractions that induced vitellogenin in fish treated with concentrations observed in surface waters (Schlenk et al., 2012). Mixtures of APs, diuron and bifenthrin caused induction in vivo, but not in vitro using primary hepatocyte cells from rainbow trout indicating direct activation of estrogen receptor by any of these compounds was not a likely mechanism. More recent studies have reported that diuron and its primary metabolites cause reductions of plasma testosterone and 11-ketotestosterone as well as histological alterations of gonads indicating anti-androgenic effects to male fish (Pereira et al., 2015). APs have been shown to modify steroid clearance enzymes and diuron metabolizing enzymes (CYPs) (Lee et al., 1996). Since diuron metabolites were shown to have anti-androgenic effects, the purpose of this study was to determine whether mixtures of AP and diuron affect biotransformation of diuron to the active metabolites, and whether enzymes that are critical in steroid biosynthesis and clearance were impacted.

In tilapia liver microsomes, diuron was readily converted to DCPU, and DCPMU (Table 2). In rats and dogs, DCPU was the predominant metabolite in the urine with small amounts of DCPMU, DCA, 3,4-dichlorophenol, and unchanged diuron detected (Hodge et al., 1967). DCPMU was the predominant metabolite $(\sim 35 \%)$ formed by NADPH catalysis in mouse liver. Interestingly, when the microsomes were incubated with DCPMU to determine whether additional demethylation occurs only 4\% conversion to DCPU was observed (Suzuki and Casida, 1981). Consistent with this observation, liver microsomes from seven mammalian species and recombinant human CYPs, only observed DCPMU formation (Abass et al., 2007). The rank order of formation based on intrinsic clearance $(V \max / K \mathrm{~K})$ was dog $>$ monkey $>$ rabbit $>$ mouse $>$ human $>$ minipig $>$ rat. These data indicate biotransformation of diuron in tilapia is qualitatively similar to that of mammals with demethylation of diuron being the predominant enzymatic reaction.

Demethylation of diuron to DCPMU was significantly induced by AP pre-treatment indicating modulation of CYPs in tilapia (Table 2). Evaluation of 12 recombinant human CYPs demonstrated that all were able to catalyze demethylation of diuron (Abass et al., 2007). The highest activities were observed with CYP1A1, CYP1A2, CYP2C19, and CYP2D6. While there are not any known homologous othrologs to CYP2C or CYP2D in fish, CYP1A activities appear to be conserved among vertebrates including fish (Schlenk et al., 2008). However, NP inhibits expression and catalytic activities of CYP1A in rodents (Lee et al., 1996), and most fish (Sturve et al., 2006). In addition, diuron was shown to potently inhibit CYP1A in humans (Abass et al., 2007). Thus, given its lack of induction of CYP1A by NP in fish, induction of diuron metabolism by NP treatment indicates other CYPs may be induced.

NP treatment has been shown to induce CYP3A in rats (Lee et al., 1996) and induce CYP3A at environmentally relevant concentrations (Arukwe et al., 1997). Since diuron and its metabolites caused a significant reduction of plasma androgens (Pereira et al., 2015), it was hypothesized that induction of CYP3A may be a mechanism by which testosterone clearance may be enhanced leading to lower plasma concentrations. However, AP treatment reduced CYP3A expression and when in mixture with diuron, failed to significantly induce vitellogenin expression (Table 3). Lower levels of CYP3A with AP treatment is inconsistent with the enhanced formation of DCPMU by AP suggesting other CYPs not modified by AP may be responsible for the demethylation of diuron. In addition, reduction of CYP content by AP is also inconsistent with dimin- 

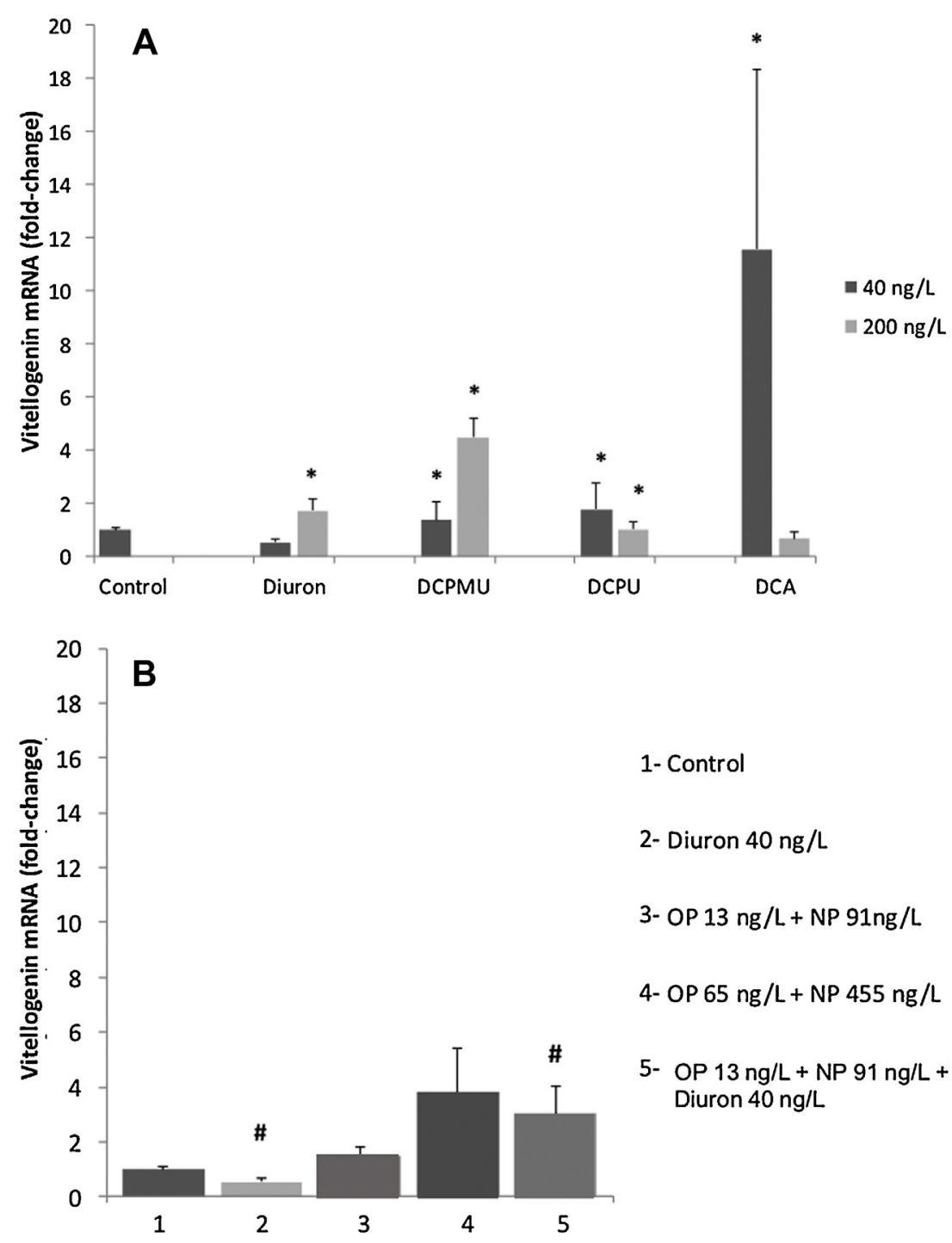

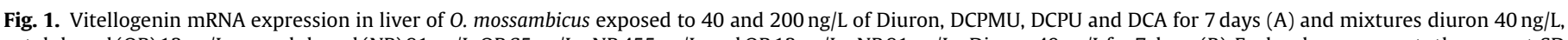

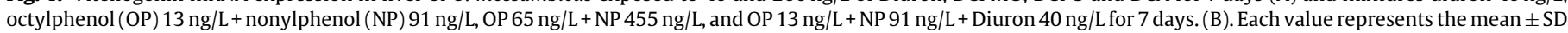
of five replicates. * represents significant difference compared to control; \# represents significant difference between treatments ( $\mathrm{p}<0.05$ ).

ished testosterone concentrations caused by diuron observed in earlier tilapia studies (Pereira et al., 2015). CYP3A is the initial clearance enzyme for testosterone in vertebrates (Schlenk et al., 2008). Hydroxylation at the $6 \beta$ and $16 \beta$ position is followed by Phase II conjugation through sulfation or glucuronidation (Schlenk et al., 2008).

Although AP/Diuron modestly induced vitellogenin transcription relative to diuron alone, demethylated metabolites and the high concentration of diuron induced vitellogenin mRNA at equal efficacies and in the case of DCPMU, a concentration dependent manner (Fig. 1A). None of the compounds are estrogen receptor agonists, but diuron has relatively weak anti-estrogenic and antiandrogenic binding activities (Orton et al., 2009). Consistent with these effects, earlier studies in Japanese medaka (Oryzias latipes) showed that exposure to $41 \mathrm{ng} / \mathrm{L}$ of diuron alone failed to induce vitellogenin (Schlenk et al., 2012). Unfortunately, higher concentrations such as the $200 \mathrm{ng} / \mathrm{L}$ in this study, were not tested in medaka. The similarity in responses between the two species at the $40 \mathrm{ng} / \mathrm{L}$ concentration is significant since the current study utilized qPCR assessment of vitellogenin transcription in the liver, whereas the medaka measurements utilized enzyme linked immunosorbent assays of hepatic vitellogenin protein. Since vitellogenin is transcriptionally regulated by estrogens, measurements of mRNA have been shown to be more sensitive in short duration assessments, while measurements of protein have a longer half-life and may be more robust during chronic exposures (Schultz et al., 2001). Responses in two species to the same compound indicate vitellogenin mRNA and/or protein in male or sexually immature animals provide consistent indications of estrogenic activity.

The mechanisms of vitellogenin induction by diuron and its demethylated metabolites are unclear, but may be related to alterations of circulating steroid hormones. Vitellogenin expression is directly controlled by E2, which is typically synthesized via CYP19 catalyzed aromatization of testosterone in the gonad. In contrast to the single form found in mammals, two genes of CYP19 have been found in teleosts; one of which is expressed mainly in the brain (CYP19a1b) and the second mainly in the gonad (CYP19a1a) (see Diotel et al., 2010 for review). While the gonadal forms are thought to be more involved in general reproduction, the brain forms appear to control many other neuroendocrine responses such as behavior. Brain aromatase activity was reduced by nearly all diuron treatments in tilapia (Fig. 2). Reductions in brain aromatase 

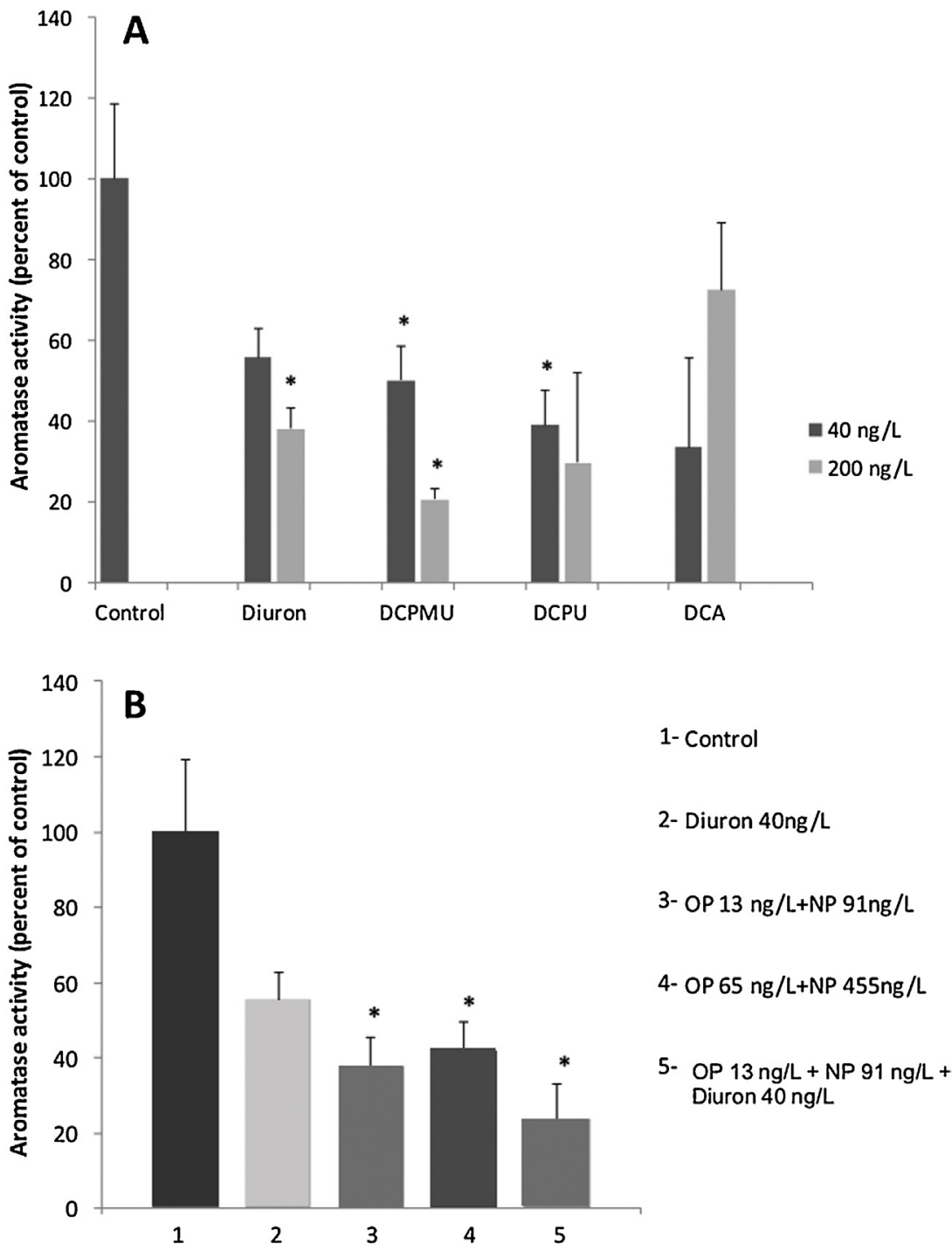

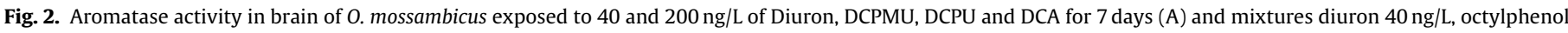

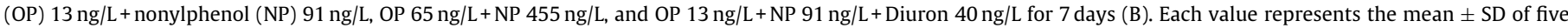
replicates * $(\mathrm{p}<0.05)$.

may have a number of significant neuroendocrine outcomes including altered release of neuronal E2 or other hypothalamic pituitary signals. Several studies have shown that diuron impaired steroidogeneis in various organisms (Cardone et al., 2008; Kojima et al., 2004) including fish (Vinggaard et al., 2000; Pereira et al., 2015). CYP19a1b is up-regulated in vivo by certain androgens, notably testosterone (Diotel et al., 2010). Although putative androgenresponsive elements were identified in the promoter region of cyp19a1b, transfection experiments showed that neither androgen receptor nor the potential response element were required for the stimulation of cyp19a1b by testosterone (Diotel et al., 2010). Consequently, the potential for diminished levels of testosterone biosynthesis caused by diuron or its metabolites may be consistent with reductions in brain aromatase in tilapia.

The fact that non-aromatized androgens (11-KT) were also diminished following treatment with diuron and its metabolites suggests that steroid biosynthesis upstream of androstenedione may also be a potential target (Pereira et al., 2015). Consistent with vitellogenin expression, DCPMU also inhibited 17ßHSD (Fig. 3). The failure of diuron alone to inhibit $17 \beta$ HSD is consistent with earlier studies that showed $17 \beta$ HSD was unaltered by diuron in fish ovarian microsomes (Thibaut and Porte, 2004). Consequently, conversion of diuron to demethylated metabolites may be a key factor in the initiation of anti-androgenic activity. Additional studies focusing on estrogen levels, gonadal aromatase (in older animals), as well as steroid biosynthetic enzymes upstream of $17 \beta \mathrm{HSD}$ or aromatase are needed to better understand this potential pathway.

\section{Conclusion}

Combined exposure to AP/Diuron caused a modest vitellogenin induction compared to diuron alone. Evaluation of targets that involve androgen transformation (CYP19) and clearance (CYP3A) suggest that enhanced biotransformation to metabolites with equivalent activity by AP, resulted in feminization (Vtg mRNA) possibly through anti-androgenization (reduced Testosterone formation in vitro). The relationships between anti-androgenization and feminization further suggest that impacts on brain aromatase as well as other steroid biosynthetic pathways may provide additional information regarding potential mechanisms for the estrogenic effects observed with diuron. 

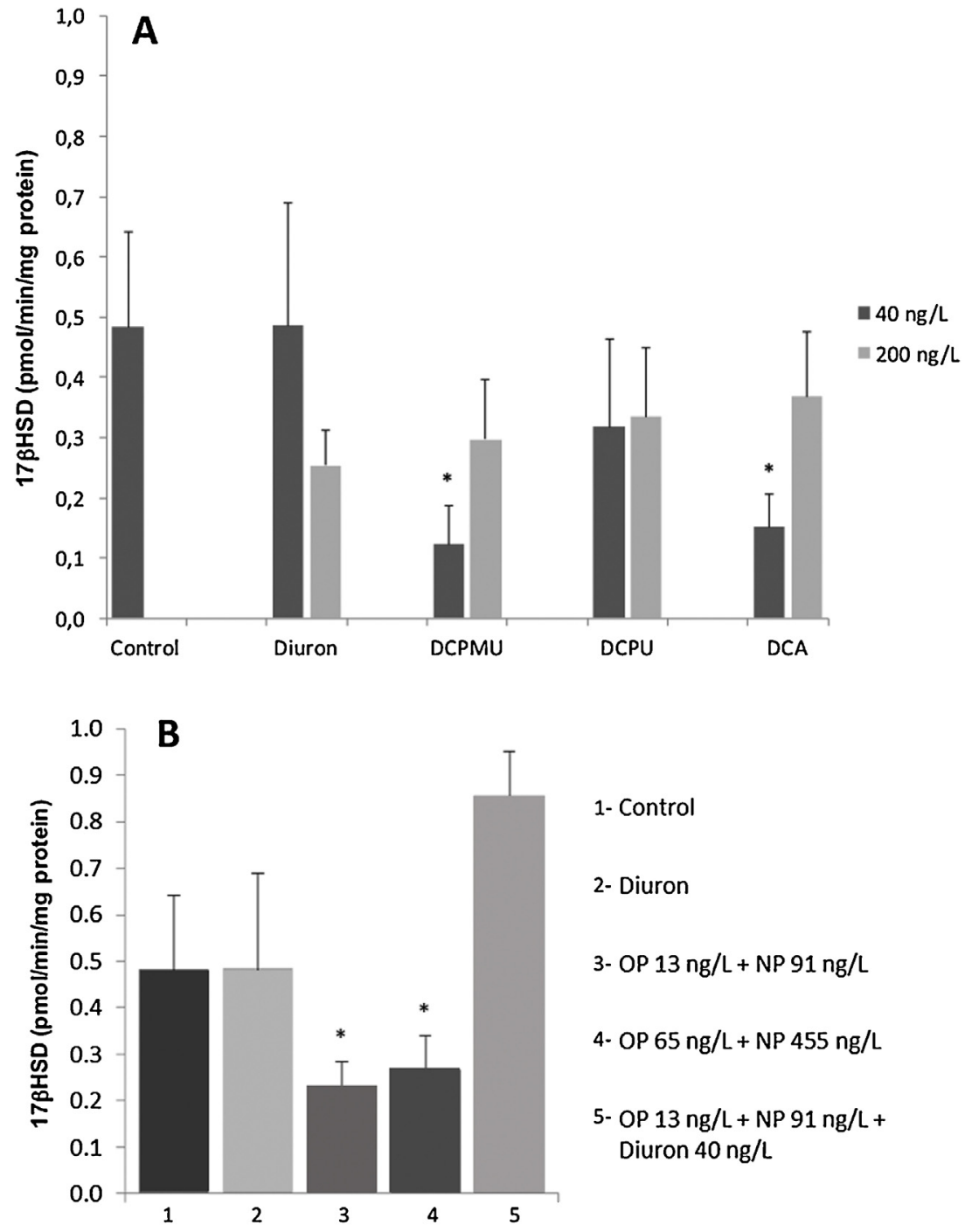

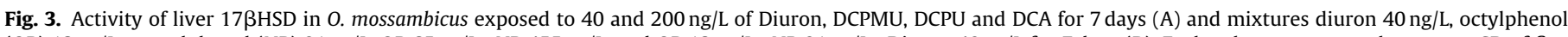

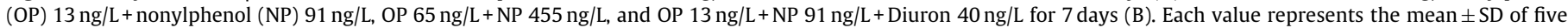
replicates * $(p<0.05)$.

\section{Acknowledgements}

The authors wish to thank Ramon Lavado for helpful discussions for enzymatic assays. This project was supported by a grant to EAA (2011/52061-8) and graduate fellowships to AAF (2014/18825-9) from FAPESP and CAPES (3000-13-3) of the Brazilian Government. Funding was also provided to EAA through CNPq (307603/2014-8) and to DS through CNPq (401884/2012-0) and the UCR, Agricultural Experiment Station Resource Allocation Support Program.

\section{References}

Abass, K., Reponen, P., Turpeinen, M., Jalonen, J., Pelkonen, O., 2007. Characteriza-tion of diuron $\mathrm{N}$-demethylation by mammalian hepatic microsomes and c-DNA expressed human cytochrome P450 enzymes. Drug Metab. Dispos. 35, 1634-1641.

Agulleiro, M.J., Anguis, V., Canavate, J.P., Martinez-Rodriguez, G., Mylonas, C., Cerda, J., 2006. Induction of spawning of captive-reared Senegal sole (Solea senegalensis) using different administration methods for gonadotropin-releasing hormone agonist. Aquaculture 257, 511-524.

Arukwe, A., Knudsen, F.R., Goksoyr, A., 1997. Fish zona radiata (eggshell) protein: a sensitive biomarker for environmental estrogens. Environ. Health Perspect. $105,418-422$.
Bradford, M.M., 1976. A rapid and sensitive method for the quantitation of microgram quantities of protein utilizing the principle of protein-dye binding. Anal. Biochem. 72, 248-254.

Cardone, A., Comitato, R., Angelini, F., 2008. Spermatogenesis, epididymis morphology and plasma sex secretion in the male lizard Podarcis sicula exposed to diuron. Environ. Res. 108, 214-223.

Diotel, N., Page, Y.L., Mouriec, K., Tong, S., Pellegrini, E., Vaillant, C., Anglade, I., Brion, F., Pakdel, F., Chung, B., Kah, O., 2010. Aromatase in the brain of teleost fish: expression, regulation and putative functions. Front. Neuroendocrinol. 31, 172-192.

Hodge, H.C., Downs, W.L., Panner, B.S., Smith, D.W., Maynard, E.A., 1967. Oral toxicity and metabolism of diuron (N-(3,4-dichlorophenyl)-N,N-dimethylurea) in rats and dogs. Food Cosmet. Toxicol. 5, 513-531.

Kojima, H., Katsura, E., Takeuchi, S., Niiyama, K., Kobayashi, K., 2004. Screening for estrogen and androgen receptor activities in 200 pesticides by in vitro reporter gene assays using Chinese hamster ovary cells. Environ. Health Perspect. 112, 524-531.

Lavado, R., Thibaut, R., Raldua, D., Martin, R., Porte, C., 2004. First evidence of endocrine disruption in feral carp from the Ebro River. Toxicol. Appl. Pharmacol. 196, 247-257.

Lavado, R., Aparicio-Fabre, R., Schlenk, D., 2013. Effects of salinity acclimation on the pesticide-metabolizing exzyme flavin-containing monooxygenase (FMO) in rainbow trout (Oncorhynchus mykiss). Comp. Biochem. Physiol. C 157, 9-15.

Lee, P.C., Patra, S.C., Stelloh, C.T., Lee, W., Struve, M., 1996. Interaction of nonylphenol and hepatic CYP1A in rats. Biochem. Pharmacol. 52, 885-889.

Lourencetti, C., Rodrigues de Marchi, M.R., Ribeiro, M.L., 2008. Determination of sugar cane herbicides in soil and soil treated with sugar cane vinasse by solid-phase extraction and HPLC-UV. Talanta 77, 701-709. 
Morcillo, Y., Albalat, A., Porte, C., 1999. Mussels as sentinels of organotin pollution: bioaccumulation and effects on P450-mediated aromatase activity. Environ. Toxicol. Chem. 18, 1203-1208.

Mylonas, C.C., Fostier, A., Zanuy, S., 2010. Broodstock management and hormonal manipulations of fish reproduction. Gen. Comp. Endocrinol. 165, 516-534.

Ohta, T., Mikake, H., Miura, C., Kamei, H., Aida, K., Miura, T., 2007.

Follicle-stimulating hormone induces spermatogenesis mediated by androgen production in Japanese eel, Anguilla japonica. Biol. Reprod. 77, 970-977.

Orton, F., Lutz, I., Kloas, W., Routledge, E.J., 2009. Endocrine disrupting effects of herbicides and pentachlorophenol: in vitro and in vivo evidence. Environ. Sci. Technol. 43, 2144-2150.

Pereira, T.S.B., Boscolo, C.N.P., Silva, D.G.H., Batlouni, S.R., Schlenk, D., Almeira, E.A., 2015. Anti-androgenic activities of diuron and its metabolites in Nile tilapia (Oreochromis niloticus). Aquat. Toxicol. 164, 10-15.

Schlenk, D., Celander, M., Gallagher, E.P., George, S., James, M., Kullman, S.W., Van den Hurk, P., Willett, K., 2008. Biotransformation in fish. In: Di Giulio, R.T. Hinton, D.E. (Eds.), The Toxicology of Fishes. Taylor \& Francis Group, New York, pp. 153-234

Schlenk, D., Lavado, R., Loyo-Rosales, J.E., Jones, W., Maryoung, L., Riar, N., Werner, I., Sedlak, D., 2012. Reconstitution studies of pesticides and surfactants exploring the cause of estrogenic activity observed in surface waters of the San Francisco Bay Delta. Environ. Sci. Technol. 46, 9106-9111.
Schultz, I.R., Orner, G., Merdink, J.L., Skillman, A., 2001. Dose-response relationships and pharmacokinetics of vitellogenin in rainbow trout after intravascular administration of $17 \alpha$-ethynylestradiol. Aquat. Toxicol. 51, 305-318

Sturve, J., Hasselberg, L., Fälth, H., Celander, M., Förlin, L., 2006. Effects of North Sea oil and alkylphenols on biomarker responses in juvenile Atlantic cod (Gadus morrhua). Aquat. Toxicol. 78S, S73-S78.

Suzuki, T., Casida, J.E., 1981. Metabolites of diuron, linuron, and methazole formed by liver microsomal enzimes in spinach plants. J. Agric. Food Chem. 29, 1027-1033.

Thibaut, R., Porte, C., 2004. Effects of endocrine disrupters on sex steroid synthesis and metabolism pathways in fish. J. Steroid Biochem. Mol. Biol. 92, 485-494.

Tixier, C., Sancelme, M., Ait-Aissa, S., Widehem, P., Bonnemoy, F., Cuer, A., Truffaut, N., Veschambre, H., 2002. Biotransformation of phenylurea herbicides by a soil bacterial strain, Arthrobacter sp. N2: structure, ecotoxicity and fate of diuron metabolite with soil fungi. Chemosphere 46, 519-526.

Tomlin, C., 1994. The Pesticide Manual, Crop Protection, tenth ed. Surrey, United Kingdom.

Vinggaard, A.M., Hnida, C., Breinholt, V., Larsen, J.C., 2000. Screening of selected pesticides for inhibition of CYP19 aromatase activity in vitro. Toxicol. in Vitro 14, 227-234.

Xie, L.T. Thrippleton, K., Irwin, M.A., Siemering, G.S., Mekebri, A., Crane, D., Berry, K., Schlenk, D., 2005. Evaluation of estrogenic activities of aquatic herbicides and surfactants using an rainbow trout vitellogenin assay. Toxicol. Sci. 87, 391-398 